\title{
The Effect of Fresh and Aged Garlic Extract-Enriched Diets on the Growth Performance of Broilers and the Oxidative Rancidity and Customer Acceptance of Chicken Meat
}

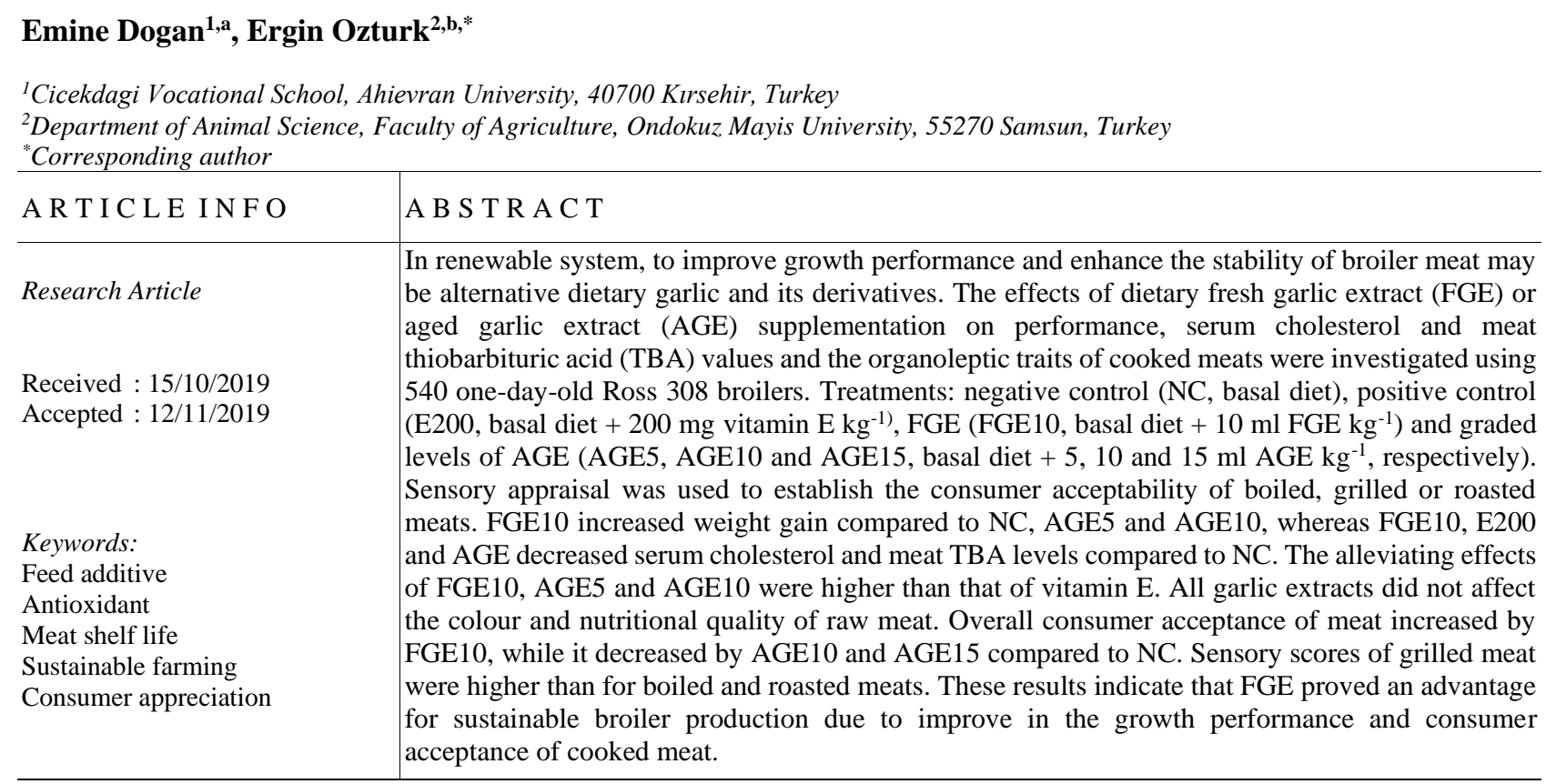

\section{Introduction}

The use of feed additives to increase the efficiency and sustainability of farms from an economic, social, and environmental point of view would be useful in many cases (Escribano, 2018). However, in general, synthetic feed additives are used to improve yield and product quality and also to increase shelf life of products in animal production. The most important problems faced by producers are availability and cost of these feed additives as well as their effects on sustainable production principles (animal welfare, equity, food safety, healthiness, environmental protection, and consumer demands). Feed additives other than synthetic for the diets of poultry are needed for renewable agriculture and food systems to help avoid some negative social and ecological impacts. Therefore, the use of natural feed additives in animal nutrition has gained importance in recent years. Indeed, in the poultry meat industry, there is a considerable problem concerning a reduction in consumer acceptability or preference and the nutritional quality of meat, as well as changes in appearance and organoleptic traits due to the process of lipid oxidation (Choi et al., 2010). Synthetic antioxidants have been used to prevent oxidation in broiler muscles and to enhance the shelf life of meat, due to the ability to scavenge free radicals (Choi et al., 2010; Aditya et al., 2017). However, there has been an increasing concern against the use of these antioxidants as they are suspected to cause mutagenic and toxic effects in the organism (Aditya et al., 2017). As such, to produce healthy and functional meat products with a natural flavour and taste, many natural antioxidants and in particular herbal powder or extracts, have been used as an alternative to synthetic antioxidants in broiler nutrition (Choi et al. 2010).

Garlic (Allium sativum L.) as powder and extracts is one of the most important vegetables as a natural growth promoter for broiler production (Ao et al., 2011; Toghyani et al., 2011; Peinado et al., 2013; Aditya et al., 2017; Sheoran et al., 2017). However, some discrepant reports exist on the effects of garlic or garlic products on the 
performance, meat quality and selected blood parameters of broilers. Indeed, there are a number of reports that indicate and describe the beneficial effects of garlic on growth performance, carcass characteristics and the meat quality of broilers (Choi et al., 2010; Toghyani et al., 2011; Sheoran et al., 2017; Karim et al., 2017; Kim et al., 2009; Hossain et al., 2014; Navidshad et al., 2018). Contrarily, Mariutti et al. (2011) and Kirkpinar et al. (2014) reported that garlic did not affect the carcass yields, breast and thigh meat composition, oxidative stability, $\mathrm{pH}$ and colour values of breast meat.

Garlic powder and extracts may increase the formation of off-flavours or an undesirable smell of broiler meat because of the penetration to the meat of their characteristic odour. It has been shown that aged garlic extract (AGE), obtained following the storage of garlic for 10-12 months, crushed or chopped might improve the flavour and biologically activate some chemical compounds in garlic. The results of in vivo (Elosta et al., 2017) and in vitro (Okada et al., 2008) studies have indicated that the antioxidant activity of AGE is higher than that of fresh garlic extract (FGE). As such, the antioxidant properties of AGE can provide favourable contributions to the shelf life and sensory properties of white meat as well as improve performance (Hossain et al., 2014).

Flavour that mainly comprises taste and aroma has been one of the most important factors affecting consumers' meat-buying behaviour and preferences (Jayasena et al., 2013; Aymerich et al., 2016). The cooked meat flavour, of high importance for the producer and the consumer, is affected by numerous factors, including diet and the method of cooking. The characteristic pungent odour of garlic penetration to the meat can occur at different levels depending on cooking methods, because many volatile flavour components or compounds of meat undergo alterations throughout storage and cooking (Perez-Alvarez et al., 2010) and can subsequently influence consumer preferences and the acceptability of cooked meats (Jayasena et al., 2013).

There is little information available on the effects of dietary FGE, AGE and $\alpha$-tocopherol on TBA levels and the visual appearance and nutritional quality of raw meat as well as consumer acceptability and organoleptic quality in terms of off-flavours or an undesirable smell of cooked meat, rather than the growth performance of broilers. To help avoid some negative social and ecological impacts of synthetic feed additives in the renewable agriculture and food systems, the suitability of garlic extracts as natural feed additives for broiler diets should be tested. The objective of this study was therefore to compare the effects of FGE and AGE as phytogenic feed additives and vitamin $\mathrm{E}$ as an antioxidant on growth performance, carcass characteristics and serum total cholesterol levels in broiler chickens. Moreover, the main aim was to determine whether these effects (if any) altered the visual appearance and nutritional quality of raw meat as well as the TBA levels, consumer acceptance and organoleptic quality in sensory terms of meat prepared using different cooking methods at $60 \mathrm{~d}$ of storage. Specifically, the study aimed to assess whether garlic extracts as natural feed additives are alternative to synthetic antioxidants for the renewable chicken production system.

\section{Materials and Methods}

\section{Experimental Birds and Treatments}

The experimental protocol of the study was approved by the local Ethical Committee of Ondokuz Mayis University for Experimental Animals which ascertained that the experiment is not an unnecessary recurrence of previous studies (Permit number: 2008/34). This experiment was conducted in a completely randomized design using 540 male broilers (Ross $308,1 \mathrm{~d}$ old, body weight $42.1 \pm 0.08 \mathrm{~g}$ ). Birds were randomly allocated to six dietary treatments for a $42 \mathrm{~d}$ feeding trial and housed in a floor barn bedded with wood shavings. Each treatment had six replicate pens with 15 birds. The experimental treatments consisted of a negative control (NC, basal diet without additive) and a positive control (E200, basal diet + $200 \mathrm{mg}$ vitamin $\mathrm{E} \mathrm{kg}^{-1}$ ), fresh garlic extract (FGA, basal diet $+10 \mathrm{ml} \mathrm{FGA} \mathrm{kg}^{-1}$ ) or graded levels of aged garlic extract (AGE5, AGE10 and AGE15, basal diet + 5, 10 and $15 \mathrm{ml}$ $\mathrm{AGE} \mathrm{kg}^{-1}$, respectively). In the study, vitamin $\mathrm{E}$ was used as the positive control because of the toxicological concerns in using synthetic antioxidants (Choi et al., 2010). FGE and AGE used in this study were prepared as described previously (Elosta et al., 2017; Majewski et al., 2017). The mush diets (Table 1) and fresh water were provided ad libitum. The light schedule consisted of a period of 23 hours (h) of light and $1 \mathrm{~h}$ of darkness. The room temperature was gradually decreased from $33 \pm 1^{\circ} \mathrm{C}$ to $21 \pm 1^{\circ} \mathrm{C}$ at $21 \mathrm{~d}$ and the temperature was then maintained until the end of the experimental period. The birds were vaccinated Newcastle $\mathrm{B}_{1}$, Gumboro and mixed Newcastle $\mathrm{B}_{1}$ and Lasoto at 10, 17 and $24 \mathrm{~d}$, respectively.

\section{Sample Collection and Measurements}

Health status was evaluated daily, whereas body weight (BW), feed intake (FI) and the feed conversion ratio (FCR, $g$ of feed: $g$ of gain) of the birds were recorded on a pen basis at 1, 21 and $42 \mathrm{~d}$. At the end of $42 \mathrm{~d}$, all animals were fasted for $8 \mathrm{~h}$ and had free access to water. A total of 12 birds from each treatment (two birds per replicate) were selected for analysis and the measurement of some studied parameters. To determinate the weight and yield of the carcass and some organs, these birds were slaughtered and chilled at $4^{\circ} \mathrm{C}$ for 12 h. The chilled carcass, abdominal fat and liver, heart and gizzard were weighed using a scale and then they were expressed as percentages of the slaughter BW (g/100 g BW).

Six birds from each treatment were selected for serum total cholesterol analyses at the age of $42 \mathrm{~d}$. Four $\mathrm{ml}$ blood was taken from the jugular veins of these animals and placed into vacutainer tubes (BD Bioscience, Franklin Lakes, NJ, USA) and refrigerated at $4{ }^{\circ} \mathrm{C}$. These blood samples were centrifuged at $2,325 \times \mathrm{g}$ for $10 \mathrm{~min}$ to separate the blood serum and then stored at $-80^{\circ} \mathrm{C}$ for further analyses of total cholesterol. The serum total cholesterol was analysed by using a kit (Biolab, Maizy, France) in an automatic analyser (Airone-200, RA, Italy).

For proximate analysis, the evaluation of $\mathrm{pH}$ and colour traits and analysis of TBA values and some organoleptic traits, right breast (pectoralis muscle) and thigh (iliotibialis muscle) muscles were vacuum packaged and kept frozen $\left(-20^{\circ} \mathrm{C}\right)$ until the time (at $60 \mathrm{~d}$ of storage). The samples from the raw meats were mashed and proximate analysis (dry matter [DM], ash, crude protein $[\mathrm{CP}]$, ether extracts $[\mathrm{EE}]$ ) was then performed according to the methods of AOAC (2005). Analyses were conducted in triplicate and the results were expressed as percentages on a DM basis. As previously described by 
Ozturk et al. (2012), the Commission Internationale de l'Elcairage (CIE), the lightness $\left(L^{*}\right)$, redness $\left(a^{*}\right)$ and yellowness $\left(b^{*}\right)$ colour values of meats and the $\mathrm{pH}$ value of raw meats were measured using a Minolta CR 300 Chroma Meter (Minolta Camera, Osaka, Japan) and a pH meter (S175CD Spear Tip; Sensorex, Garden Grove, CA, USA).

The TBA values of the thigh meat samples stored at $4^{\circ} \mathrm{C}$ for $5 \mathrm{~d}$ and then $-18^{\circ} \mathrm{C}$ for $60 \mathrm{~d}$ were analysed at the Marmara Research Centre (Scientific and Technological Research Council of Turkey) according to the procedure of AOAC (2005) and Ganhao et al. (2011).

The breast meats were frozen and sealed at $-18^{\circ} \mathrm{C}$ for 60 $\mathrm{d}$ until sensory appraisal. Before sensory appraisal, breast meats were thawed at $4^{\circ} \mathrm{C}$ for $72 \mathrm{~h}$, The breast meats were then prepared and moulded properly for each of the three precooking processes ( $\mathrm{n}=12$ for each cooking method) and subjected to boiling, grilling or roasting. For the boiling method, the meats were packed in a plastic bag and immersed in a thermostat controlled water bath (Memmert WB 14, Germany), while grilling was conducted on an electric griddle (Repagas, 550 series, Madrid, Spain). After the meats were covered with aluminium foil, roasting was performed in a microwave oven (Unox ${ }^{\circledR}$, Mod. GN2.1, Cadonegue, Italy). To ensure the meats were cooked, the internal temperatures of the meat during cooking by boiling, grilling or roasting were adjusted to 80,200 and $150^{\circ} \mathrm{C}$ at approximately 30,8 and 16 min, respectively. For this purpose, the internal temperatures in the core of the samples were measured using a digital probe thermometer (Testo thermocouple, Mod. 735-1, Lenzkirch, Germany). The cooked meats were placed in trays and were kept at room temperature for 20-30 min. These meats were divided into equal sized pieces (approximately $1 \mathrm{~cm}^{3}$ ) with a knife and randomly coded with three-digit numbers before being offered to the panellists after being warmed up to $37^{\circ} \mathrm{C}$ for $10 \mathrm{~min}$ in an oven (if necessary). The cooked products were then evaluated by untrained sensory panellists. Sensory appraisal was performed by 10 (five men and five women) panellists, who were regular consumers of chicken meat products and ranged from 21 to 55 years of age. For sensory appraisal, general requirements (conversation area, screening and pre-training of the assessors) and conditions (conducive, pleasant and quiet environment) were provided as described in the sensory texts. The six important sensory characteristics (appearance, smell, hardness, juiciness, brittleness and flavour) of meat were rated by using a hedonic scale of nine points from extremely disliked (1) to extremely liked (9) as previously explained (Kemp et al., 2009). The overall acceptability was calculated, considering appearance, smell, hardness, juiciness, brittleness and flavour (each with 16.66\%).

\section{Statistical Analyses}

All statistical analyses were performed with the SPSS Statistics package (IBM 18 SPSS Statistics, Version 21.0, IBM Corp., Armonk, NY). The pen mean values were used as the experimental unit. Percentage data were subjected to arcsine transformation before analysis. Data, except for sensory data, were evaluated by ANOVA using the compare mean procedure of the program package according to a randomized complete block design. A Kruskal-Wallis analysis was applied to the sensory data. However, there were no differences among these variables. Consequently, the studied sensory characteristics for each dietary treatment and cooking method were combined and then were studied by ANOVA, including the effects of diet (six diets) and cooking method (three methods) and their interaction, using the GLM procedure. Significant differences were determined by using Duncan's multiple range test and were deemed significant at $\mathrm{P}<0.05$. The results were stated as the mean with a pooled standard error of the mean (SEM).

Table 1 Ingredient and nutrient composition $\left(\mathrm{g} \mathrm{kg}^{-1}\right.$, as fed basis) of the basal diet

\begin{tabular}{|c|c|c|c|}
\hline Ingredients & Starter $(0-10 \mathrm{~d})$ & Grower $(11-24 \mathrm{~d})$ & Finisher $(25-42 \mathrm{~d})$ \\
\hline Maize & 520.38 & 560.17 & 583.82 \\
\hline Soybean meal & 300.00 & 264.10 & 233.11 \\
\hline Full fat soybean & 135.00 & 124.63 & 134.05 \\
\hline Vegetable oil & 7.72 & 20.00 & 20.00 \\
\hline Limestone & 24.23 & 20.17 & 19.10 \\
\hline Dicalcium phosphate & 1.51 & 2.00 & 1.77 \\
\hline Salt & 3.30 & 3.30 & 3.30 \\
\hline Vit. and min. premix ${ }^{*}$ & 3.50 & 3.50 & 3.50 \\
\hline L-lysine, $78 \%$ & 1.68 & 0.39 & 0.27 \\
\hline DL-methionine, $99 \%$ & 3.48 & 2.74 & - \\
\hline L-Threonine, \%99 & 0.20 & - & - \\
\hline \multicolumn{4}{|c|}{ Nutrients composition } \\
\hline Metabolizable energy (ME, $\mathrm{MJ} \mathrm{kg}^{-1}$ ) & 12.77 & 13.19 & 13.57 \\
\hline Crude protein & 232.5 & 215.4 & 196.1 \\
\hline Crude fibre & 34.4 & 35.1 & 35.3 \\
\hline L-Lysine & 14.3 & 12.4 & 10.9 \\
\hline DL-Methionine & 5.1 & 4.5 & 4.1 \\
\hline Threonine & 9.4 & 8.3 & 7.4 \\
\hline Methionine-Cystine & 10.2 & 9.0 & 8.5 \\
\hline Tryptophan & 2.4 & 2.0 & 1.8 \\
\hline Calcium & 10.5 & 9.2 & 8.0 \\
\hline Available phosphorus & 5.0 & 4.6 & 4.3 \\
\hline
\end{tabular}

*Vitamin and mineral premix; Supplied per kilogram of diet: 12000 IU retinol; 3000 IU cholecaciferol; 70 mg IU tocopherol; 0.03 mg cyanocobalamin; $6 \mathrm{mg}$ riboflavin; $12 \mathrm{mg}$ pantothenate; $25 \mathrm{mg}$ niacin; $200 \mathrm{mg}$ choline; $3 \mathrm{mg}$ thiamine; $70 \mu \mathrm{g}$ biotin; $60 \mathrm{mg}$ zinc; $80 \mathrm{mg}$ manganese; $60 \mathrm{mg}$ iron; $5 \mathrm{mg}$ copper; $1 \mathrm{mg}$ iodine; $0.15 \mathrm{mg}$ selenium. 


\section{Results}

During the experimental period, the FGE10 treatment increased weight gain compared to NC, AGE5 and AGE10, whereas the FGE10 and AGE15 treatments increased FI compared to AGE5 and AGE10 ( $\mathrm{P}<0.05$, Table 2). Additionally, the weight gain of AGE15 birds was higher than in AGE5 chickens $(\mathrm{P}<0.05)$. At $21 \mathrm{~d}$ of age, the FI of birds in the FGE10 and AGE10 treatment groups were higher than those given the other treatments. No differences in FCR and mortality among the dietary treatments were observed at 21 and $42 \mathrm{~d}$ of age $(\mathrm{P}>0.05)$.

The relative weight of the carcass, edible internal organs (heart, liver and gizzard), abdominal fat and dressing percentage were not influenced by the dietary treatments $(\mathrm{P}>0.05$, Table 3). Similarly, there were no differences among treatment groups in terms of nutrient (DM, CP, ash and EE) contents (Table 4) and the CIELab and $\mathrm{pH}$ values (Table 5) of breast and thigh meats $(\mathrm{P}>0.05)$. Figure 1 illustrates that the FGE10 (121 mg/dL), E200 (162 $\mathrm{mg} / \mathrm{dL})$ and all AGE treatments $(132,157$ and $138 \mathrm{mg} / \mathrm{dL}$, respectively) decreased $(\mathrm{P}<0.05)$ the serum total cholesterol compared to NC (171 mg/dL). The meat TBA levels of the FGE10 (0.11 g MDA/kg) and AGE5 (0.12 g MDA $/ \mathrm{kg})$ broilers were lower $(\mathrm{P}<0.05$, Figure 2) than those of the NC, E200 and AGE15 birds (0.64, 0.31 and $0.24 \mathrm{~g} \mathrm{MDA} / \mathrm{kg}$, respectively). However, the TBA level of meat from the AGE10 broilers (0.17 $\mathrm{g}$ MDA/kg) was similar to the TBA levels of the FGE10, AGE5 and AGE15 birds.

Table 2 Live weight gain, feed intake and feed conversion ratio of broilers fed on diets with fresh garlic extract, vitamin E and graded levels of aged garlic extract

\begin{tabular}{|c|c|c|c|c|c|c|c|c|}
\hline Days & $\mathrm{NC}$ & E200 & FGE10 & AGE5 & AGE10 & AGE15 & SEM & P-Value \\
\hline \multicolumn{9}{|c|}{ Live weight gain (g/bird) } \\
\hline $1-21$ & 805.4 & 835.0 & 867.9 & 831.7 & 830.0 & 821.7 & 6.49 & NS \\
\hline $21-42$ & 1814 & 1808 & 1900 & 1741 & 1760 & 1907 & 20.00 & NS \\
\hline $1-42$ & $2620^{\mathrm{bc}}$ & $2660^{\mathrm{abc}}$ & $2768^{\mathrm{a}}$ & $2572^{\mathrm{c}}$ & $2590^{\mathrm{bc}}$ & $2728^{\mathrm{ab}}$ & 21.05 & $*$ \\
\hline \multicolumn{9}{|c|}{ Feed intake (g/bird) } \\
\hline $1-21$ & $932^{\mathrm{b}}$ & $934^{\mathrm{b}}$ & $985^{\mathrm{a}}$ & $934^{\mathrm{b}}$ & $968^{\mathrm{a}}$ & $938^{b}$ & 4.56 & $* * *$ \\
\hline $21-42$ & 3683 & 3717 & 3866 & 3551 & $357^{3}$ & 3878 & 39.66 & NS \\
\hline $1-42$ & $4825^{\mathrm{ab}}$ & $4950^{\mathrm{ab}}$ & $5055^{\mathrm{a}}$ & $4733^{\mathrm{b}}$ & $4765^{\mathrm{b}}$ & $5011^{\mathrm{a}}$ & 34.79 & $*$ \\
\hline \multicolumn{9}{|c|}{ Feed conversion ratio $\left(\mathrm{g} \mathrm{g}^{-1}\right)$} \\
\hline $1-21$ & 1.15 & 1.11 & 1.13 & 1.12 & 1.16 & 1.14 & 0.009 & NS \\
\hline $21-42$ & 2.03 & 2.05 & 2.03 & 2.03 & 2.03 & 2.03 & 0.004 & NS \\
\hline $1-42$ & 1.84 & 1.85 & 1.82 & 1.83 & 1.84 & 1.83 & 0.003 & NS \\
\hline
\end{tabular}

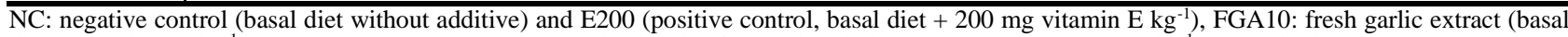
diet $+10 \mathrm{ml} \mathrm{FGA} \mathrm{kg}^{-1}$ ), AGE5, AGE10 and AGE15 (graded levels of AGE, basal diet + 5, 10 and $15 \mathrm{~m} 1$ AGE kg-1, respectively). SEM: standard error of mean, Significant difference is shown by different superscripts in the same row $(\mathrm{P}<0.05)$. NS $=$ Not significant $(\mathrm{P}>0.05)$, $*$ P $<0.05$, $* * * ~ P<0.001$, Values represent the mean of six replicate with 15 birds for each treatment.

Table 3 Livability (\%), carcass weight $(\mathrm{g})$ and relative weights ( $\mathrm{g} / 100 \mathrm{~g}$ body weight) of carcass, edible inner organs and abdominal fat of broilers fed on diets with fresh garlic extract, vitamin E and graded levels of aged garlic extract

\begin{tabular}{|c|c|c|c|c|c|c|c|c|}
\hline Traits & $\mathrm{NC}$ & E200 & FGE10 & AGE5 & AGE10 & AGE15 & SEM & P-Value \\
\hline \multicolumn{9}{|c|}{ Weight of } \\
\hline Hot carcass & 1993 & 1938 & 2114 & 2011 & 2078 & 2103 & 22.7 & NS \\
\hline Cold carcass & 1971 & 1914 & 2083 & 1979 & 2018 & 2061 & 22.4 & NS \\
\hline \multicolumn{9}{|c|}{ Relative weight of } \\
\hline Cold carcass & 75.2 & 75.0 & 75.3 & 76.9 & 77.9 & 75.6 & 0.40 & NS \\
\hline Hearth & 0.48 & 0.50 & 0.52 & 0.52 & 0.53 & 0.51 & 0.309 & $\mathrm{NS}$ \\
\hline Liver & 2.23 & 2.28 & 2.29 & 2.40 & 2.36 & 2.24 & 0.345 & NS \\
\hline Gizzard & 1.19 & 1.13 & 1.16 & 1.14 & 1.17 & 1.04 & 0.340 & $\mathrm{NS}$ \\
\hline Abdominal fat & 1.76 & 1.68 & 1.71 & 1.65 & 1.67 & 1.66 & 0.283 & NS \\
\hline Livability & 95.6 & 96.7 & 96.7 & 96.7 & 95.6 & 96.7 & 0.42 & NS \\
\hline
\end{tabular}

Abbreviations are as shown in Table 2. NS: Not significant ( $>>0.05)$, Values represent the mean of six replicate with two birds for each treatment.

Table 4 Nutrients composition of breast and thigh meats from broilers fed on diets with fresh garlic extract, vitamin $\mathrm{E}$ and graded levels of aged garlic extract

\begin{tabular}{l|cccccccc}
\hline \multicolumn{1}{c}{ Nutrients } & NC & E200 & FGE10 & AGE5 & AGE10 & AGE15 & SEM & P-Value \\
\hline \multicolumn{7}{c}{ Thigh meat } \\
\hline Dry matter & 25.4 & 25.9 & 26.5 & 25.7 & 26.5 & 26.5 & 0.045 & NS \\
Crude protein & 20.6 & 21.1 & 21.7 & 20.9 & 21.7 & 21.7 & 0.055 & NS \\
Ether extracts & 3.82 & 3.82 & 3.81 & 3.81 & 3.82 & 3.83 & 0.021 & NS \\
Ash & 0.99 & 0.98 & 0.99 & 0.99 & 0.98 & 0.99 & 0.009 & NS \\
\hline \multicolumn{7}{c}{ Breast meat } \\
\hline Dry matter & 25.7 & 26.0 & 26.8 & 25.6 & 25.8 & 26.0 & 0.073 & NS \\
Crude protein & 23.5 & 23.8 & 24.6 & 23.4 & 23.6 & 23.8 & 0.018 & NS \\
Ether extract & 1.27 & 1.26 & 1.25 & 1.25 & 1.27 & 1.28 & 0.013 & NS \\
Ash & 0.94 & 0.94 & 0.94 & 0.94 & 0.94 & 0.93 & 0.001 & NS \\
\hline Abbreviations are as shown in table 2. NS: Not significant (P>0.05), Values represent the mean of six replicate with two birds for each treatment.
\end{tabular}


Table 5 The CIELab colour and $\mathrm{pH}$ values of meats from broilers fed on diets supplemented garlic extract, vitamin E and graded levels of aged garlic extract

\begin{tabular}{l|cccccccc}
\hline \multicolumn{1}{l|}{} & NC & E200 & FGE10 & AGE5 & AGE10 & AGE15 & SEM & P-Value \\
\hline \multicolumn{8}{c}{} & \multicolumn{7}{c}{ Breast meat } & & & & \\
\hline $\mathrm{L}^{*}$ & 68.69 & 67.23 & 68.19 & 67.02 & 68.89 & 66.87 & 0.335 & $\mathrm{NS}$ \\
$\mathrm{a}^{*}$ & 3.12 & 2.99 & 2.84 & 3.48 & 3.04 & 2.83 & 0.105 & $\mathrm{NS}$ \\
$\mathrm{b}^{*}$ & 3.18 & 3.34 & 3.20 & 3.01 & 3.31 & 3.28 & 0.222 & $\mathrm{NS}$ \\
$\mathrm{pH}$ & 5.69 & 5.67 & 5.63 & 5.62 & 5.65 & 5.67 & 0.026 & $\mathrm{NS}$ \\
\hline \multicolumn{8}{c}{ Thigh meat } \\
\hline $\mathrm{L}^{*}$, lightness & 62.44 & 62.30 & 63.84 & 63.78 & 62.67 & 63.79 & 0.565 & $\mathrm{NS}$ \\
$\mathrm{a}^{*}$, redness & 6.43 & 6.55 & 6.36 & 6.44 & 6.33 & 6.36 & 0.191 & $\mathrm{NS}$ \\
$\mathrm{b}^{*}$, yellowness & 2.47 & 2.36 & 2.43 & 2.41 & 2.47 & 2.41 & 0.439 & $\mathrm{NS}$ \\
$\mathrm{pH}$ & 6.16 & 6.13 & 6.12 & 6.11 & 6.14 & 6.13 & 0.028 & $\mathrm{NS}$ \\
\hline
\end{tabular}

Abbreviations are as in Table 2. NS: Not significant (P>0.05), Values represent the mean of six replicate with two birds for each treatment.

Table 6 The overall sensory score of breast meat subjected to assorted cooking methods (CM) and from broilers fed on diets supplemented garlic extract, vitamin $\mathrm{E}$ and graded levels of aged garlic extract

\begin{tabular}{l|cccccccc}
\hline \multicolumn{1}{c|}{ CM } & NC & E200 & FGE10 & AGE5 & AGE10 & AGE15 & Overall & SEM \\
\hline Boiled & 6.83 & 7.17 & 7.17 & 6.83 & 7.00 & 6.67 & $6.94^{\mathrm{b}}$ & 0.079 \\
Grilled & 7.83 & 8.17 & 8.33 & 8.50 & 8.17 & 8.17 & $8.19^{\mathrm{a}}$ & 0.078 \\
Roasted & 7.00 & 6.83 & 7.00 & 6.67 & 6.17 & 6.33 & $6.67^{\mathrm{c}}$ & 0.098 \\
Overall & $7.22^{\mathrm{b}}$ & $7.39^{\mathrm{b}}$ & $7.50^{\mathrm{a}}$ & $7.33^{\mathrm{b}}$ & $7.11^{\mathrm{c}}$ & $7.06^{\mathrm{c}}$ & & \\
SEM & 0.129 & 0.183 & 0.185 & 0.243 & 0.212 & 0.221 & & \\
\hline
\end{tabular}

Abbreviations are as shown in Table 2. Values are mean of 12 breast meat from six replicates which they were scored with 10 panelists, The overall consumer' acceptability was calculated considering the sensory characteristics such as appearance, smell, hardness, juiciness, brittleness and flavor (each with $16.66 \%$ ). Significant difference is shown by different superscripts in the same row and column for dietary treatment and cooking methods, respectively $(\mathrm{P}<0.05)$.

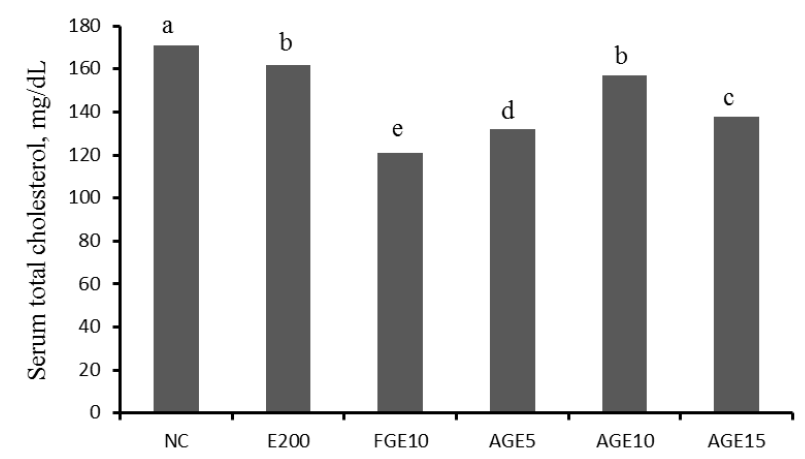

Figure 1 The serum total cholesterol of broilers fed on diets supplemented fresh garlic extract, vitamin and graded levels of aged garlic extract

The appearance, smell, hardness, juiciness, brittleness and flavour of the cooked meats belonging to all treatment groups were liked by the panellists. The panellists gave high scores for the meats cooked by different methods. The scores provided by the panellists for grilled meats shifted from moderately liked to extremely liked, compared to the boiled and roasted meats (data not shown). Dietary treatment and cooking method imparted a dramatic influence on the overall consumer acceptance of meat $(\mathrm{P}<0.001)$, whereas the interaction between the factors had a non-significant effect $(\mathrm{P}=0.120)$. Overall consumer acceptance of the meat was increased by the FGE10 treatment, while it was decreased by the AGE10 and AGE15 treatments compared to NC (Table 6). The sensory score (or overall consumer acceptance) of the grilled meat was higher than for the boiled and roasted meats $(\mathrm{P}<0.05)$. Roasted meats had the lowest sensory score.

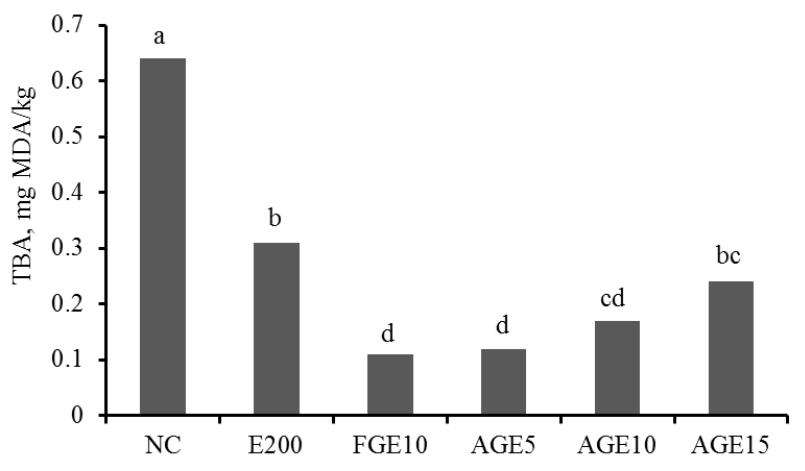

Figure 2 The thiobarbituric acid (TBA) values of meats from broilers fed on diets supplemented garlic extract, vitamin $\mathrm{E}$ and graded levels of aged garlic extract. MDA: malondialdehyde

\section{Discussion}

In the present study, growth performance was improved by dietary supplementation of FGE due to increasing FI. This result does not confirm the idea that dietary garlic supplementation may decrease FI due to its characteristic pungent odour and that the ageing process may improve the flavour and some bioactive ingredients in garlic powder, or that diets supplemented with AGE may improve the growth performance of broilers (Hossain et al., 2014). The performance results of the present study suggest that the amount and form of antimicrobial active compounds might be varied by the ageing of garlic bulbs, although the bioactive phenolic compounds of FGE and AGE were not analysed. The performance results are in agreement with previous studies (Sheoran et al., 2017; Hossain et al., 2014; Navidshad et al., 2018) in which broiler performance was 
positively affected by garlic supplementation. In contrast, in some studies, the dietary supplementation of garlic powder (Issa and Omar, 2012; Fazli et al., 2015) did not affect the FI and growth performance in broilers prior to slaughter. The increased FI in the present study may be attributed to the fact that the antimicrobial active compounds of garlic might stimulate appetite and improve endogenous digestive enzyme secretion (Navidshad et al., 2018). Accordingly, FGE10 had a beneficial effect on BW gain until slaughter due to an increase in the FI of the FGE10 birds as reported in the previous study (Ao et al., 2011). However, this situation was not confirmed by the BW gain of AGE15 birds having a higher FI. Moreover, FGE and AGE increased FI at the starter phase, but this effect was not reflected in either the grower phase or the entirety of the experiment compared to the NC and E200 groups. The BW gains of broilers were not improved by increasing levels of dietary AGE supplementation, in disagreement with previous studies (Sheoran et al., 2017; Hossain et al., 2014; Navidshad et al., 2018). As reported in this paper, it has been noted that dietary garlic supplementation did not affect the FCR of broiler chickens (Navidshad et al., 2018).

Our results regarding serum total cholesterol levels confirmed that dietary garlic products reduced the blood cholesterol level in broilers (Choi et al., 2010; Moradi et al., 2013). This may be explained by the fact that garlic is effective in the regulation of lipid and cholesterol metabolism (Karim et al., 2017), similarly to the effect of dietary vitamin E (Zdanowska-Sąsiadek et al., 2016). The increase in both FI and BW gain in FGE fed birds may be attributed to FGE's growth promoting effects and antioxidant and hypocholesterolemic activities in the regulation of lipid metabolism (Choi et al., 2010) and to a lowering of the animal's physiological and metabolic stress, by contributing to animal welfare (Kim et al., 2009). However, the reduced serum cholesterol levels in the AGE and vitamin $\mathrm{E}$ birds did not alter the growth or feed efficiency of the chickens. As a consequence, the exact mechanism of AGE and vitamin $\mathrm{E}$ is not well understood.

The results of the present study are in agreement with previous observations indicating that garlic powder, extract or oils did not affect the liveability, carcass yield and characteristics, or the relative weights of edible inner organs and abdominal fat (Toghyani et al., 2011; Hossain et al., 2014; Kirkpinar et al., 2014). Conversely, it has been reported that the addition of garlic bulb powder to broiler diets increased the weight of internal organs such as the heart, gizzard and liver, and the $\mathrm{CP}$ content of thigh muscle (Kim et al., 2009), while it decreased abdominal fat and the EE content of the thigh muscle (Kim et al., 2009; Ashayerizadeh et al., 2009). In agreement with the present study, Kim et al. (2009) and Kirkpinar et al. (2014) indicated that dietary garlic oil did not affect the DM, ash, $\mathrm{CP}$ and EE contents of the breast and thigh meats. Similarly, Chae et al. (2006) reported that $\alpha$-tocopherol acetate supplementation increased the $\mathrm{CP}$ and $\mathrm{EE}$ content of the broiler meat.

The colour of broiler meat is an important parameter, because it is an indication of freshness and high-quality for consumers (Hossain et al., 2014). However, the results for the CIELab colour and $\mathrm{pH}$ values of breast and thigh meats suggest that the meats of broilers fed a diet with vitamin
FGE or AGE will not have an influence on the retail purchasing decisions of consumers. Indeed, consumers use colour as an indicator of spoilage and shelf-life by visual appearance (Jayasena et al., 2013; Kop-Bozbay and Ocak, 2015; Wideman et al., 2016). The muscle $\mathrm{pH}$ and meat colour are highly correlated and the functionality of the meat is of great importance to processors of fresh and further processed products when it directly affects the profit and shelf-life of the product. The meat colour is associated with the degree of meat oxidation (Sohaib et al., 2015). In the present study, the CIELab and $\mathrm{pH}$ values of meat were not affected by dietary FGE, vitamin E or AGE as reported by Chae et al. (2006). In addition, the results with respect to the CIELab values did not support the idea that vitamin E-enriched diets improve the overall meat quality (Chae et al., 2005; Chae et al., 2006). Kim et al., (2009) proposed that dietary garlic oil supplementation did not affect the $\mathrm{pH}$ and $b^{*}$ value of breast meat, but decreased the $L^{*}$ value and increased the $a^{*}$ value. Contrary to our results, there are a number of studies that reported dietary garlic or its bioactive phenolic compounds to have either no or an inconsistent effect on meat colour. Indeed, garlic and garlic products used in the broiler diet have been found to decrease the $L^{*}$ (Choi et al., 2010; Kirkpinar et al., 2014) and $b^{*}$ (Kirkpinar et al., 2014) values and increase the $a^{*}$ (Choi et al., 2010; Ao et al., 2011; Hossain et al., 2014; Abdullah et al., 2010) and $b^{*}$ (Ao et al., 2011; Abdullah et al., 2010) values of chicken meat. Similarly, AGE broiler diets did not affect the $\mathrm{pH}$ value, ${ }^{9,10}$ whereas a fermented garlic-enriched diet decreased the $\mathrm{pH}$ value of breast meat (Choi et al., 2010; Ao et al., 2011; Kirkpinar et al., 2014; Abdullah et al., 2010).

The results on lipid oxidation, analysed by the formation of TBA during processing suggest that supplemental FGE, AGE and vitamin $\mathrm{E}$ have a protective role in terms of rancidity and are in agreement with the reports of several studies on supplemental vitamin $E^{20,21}$ and garlic products (Choi et al., 2010; Ao et al., 2011; Kim et al., 2009; Kirkpinar et al., 2014). Garlic extracts include antioxidant substances such as vitamins C, E and A and amino acids such as cysteine, glutamine, isoleucine and methionine, which help protect the cells from damage by free radicals, explaining why the garlic extracts used in the present study have a more effective alleviative impact than vitamin $\mathrm{E}$.

Our results concerning sensory appraisal confirmed the results of several previous studies (Choi et al., 2010; Ao et al., 2011) in which different levels of garlic in broiler diets did not affect sensory parameters such as appearance, flavour, juiciness, texture and general acceptability. In contrast to these results and those of the present study, some other researchers have reported that garlic increased the juiciness (Kim et al., 2009; Kirkpinar et al., 2014) and improved the flavour, tenderness, overall acceptability (Jahan et al., 2005) and sensory scores (Toghyani et al., 2011). Moreover, Abdullah et al. (2010) reported that the juiciness of broiler meat was decreased by dietary garlic supplementation.

Consumers' liking for and acceptance of meat products are strongly affected by the cooking method due to an alteration in the aroma profile of meats subjected to assorted cooking methods (Jayasena et al., 2013; PerezAlvarez et al., 2010). Perez-Alvarez et al. (2010) stated that 
besides the natural compounds in meat, broiler diet contributes to the flavour, but this can either positively or negatively affect the flavour of chicken meat (Jayasena et al., 2013). However, in our study, the overall consumer acceptance result does not support the contention that broilers fed a diet containing FGE may result in garlic flavoured meat (Peinado et al., 2013; Toghyani et al., 2011) and that dietary vitamin E supplementation might increase the sensory scores in acceptability terms due to the $\alpha$ tocopheryl acetate content (Jahan et al., 2005). The impact of cooking methods on overall consumer acceptance of meats from broilers fed on enriched vitamin E, FGE and AGE diets can be explained by the extent of tissue disruption and the nature of chemical reactions due to the influence of cooking duration and temperature ${ }^{35}$. Indeed, it has been noted that the flavour intensities or the development of off-flavour compounds generated at low temperatures are of lower quantities than are generated at higher temperatures (Jayasena et al., 2013; Liu et al., 2012). In the current study, the cooking duration and temperature of the grilling method were shorter and higher respectively than in other methods.

Inconclusive outcomes among the previously published studies and the present study may result from the fact that the studies differed not only in the broiler strains used, but also in the husbandry conditions, growing durations and age of the birds, as well as in the time points, differences in the species, level, form and growing conditions of garlic used. Garlic is known as a source of bioactive compounds that have drawn attention due to their antimicrobial and antioxidant properties (Toghyani et al., 2011; Sheoran et al., 2017). As reported in previous studies, the concentration of the total bioactive compound varies according to the cultivars of garlic, weather conditions during harvest, crop production practices, location as well as storage conditions, stage of maturation and processing conditions (Prati et al., 2014). In addition, the divergence of the results obtained in various studies may be attributed to the differences in preparation procedures, the stability of effective components, the period of the study, the different levels of garlic and the animals used in each study.

\section{Conclusions}

The results of the present study indicated that: i) dietary supplementation of FGE improved growth performance due to an increase in FI, without affecting FCR; ii) dietary vitamin E, FGE and all levels of AGE induced the regulation of lipid metabolism and the inhibition of lipid oxidation due to a reduction in serum cholesterol and meat TBA levels, an indicator of the enhanced shelf life or rancidity of meat, respectively and; iii) the dietary treatments and cooking methods did not cause a measurable variation in the visual appearance and nutritional quality of raw meat and sensory traits in terms of off-flavours or the undesirable smell of meats subjected to assorted cooking methods, but the FGE treatment and the grilling method improved the overall consumer acceptance of broiler meat. These results reveal that fresh garlic extract and the lowest level of aged garlic extract had a higher impact in lowering the oxidative rancidity and serum cholesterol compared to vitamin E. Based on these results, it can be said that garlic has potential to be used in the renewable animal and food production systems. Our study indicated that it may prove relevant to reassess the performance and meat quality traits affected by broiler diets with garlic extracts.

\section{Funding}

This research was financially supported by Ondokuz Mayis University (Grant No. PYO.ZRT.1904.11.005) and it did not receive external funding.

\section{Acknowledgments}

The authors thank Dr. Nuh Ocak for providing highlights writing the manuscript.

\section{Conflict of Interest}

The authors declare no conflict of interest. The founding sponsors had no role in the design of the study; in the collection, analyses or interpretation of data; in the writing of the manuscript; and in the decision to publish the results.

\section{References}

Abdullah AY, Mahmoud KZ, Nusairat BM and Qudsieh RI. 2010. Small intestinal histology, production parameters, and meat quality as influenced by dietary supplementation of garlic (Allium sativum) in broiler chicks. Italian Journal of Animal Science 9, 414-419.

Aditya S, Ahammed M, Jang SH and Ohh SJ. 2017. Effects of dietary onion (Allium cepa) extract supplementation on performance, apparent total tract retention of nutrients, blood profile and meat quality of broiler chicks. AsianAustralasian Journal of Animal Sciences 30, 229-235.

Ao X, Yoo JS, Zhou TX, Wang JP, Meng QW, Yan L, Cho JH and Kim IH. 2011. Effects of fermented garlic powder supplementation on growth performance, blood profiles and breast meat quality in broilers. Livestock Science 141, 85-89.

AOAC, 2005. Official Methods of Analysis, 18th ed. Association of Official Analytical Chemists, Washington, DC.

Ashayerizadeh O, Dastar B, Shargh M, Ashayerizadeh A, Rahmatnejad E and Hossaini SMR. 2009. Use of garlic (Allium sativum), black cumin seeds (Nigella sativa) and wild mint (Mentha longifolia) in broiler chickens diets. Journal of Animal Veterinary Advances 8, 1860-1863.

Aymerich T, Picouet PA and Monfort JM. 2008. Decontamination technologies for meat products. Meat Science 78, 114-129.

Chae BJ, Lohakare JD and Choi JY. 2006. Effects of incremental levels of $\alpha$-tocopherol acetate on performance, nutrient digestibility and meat quality of commercial broilers. AsianAustralasian Journal of Animal Sciences 19, 203-208.

Chae BJ, Lohakare JD, Choi JY, Han KN, Yong JS, Won HK, Park, YH and Hahn TW. 2005. The efficacy of vitamin Epolyethylene glycol complex on growth performance, chicken meat quality and immunity in broilers. Journal of Animal and Feed Sciences 14, 125-138.

Choi H, Park WY and Kim YJ. 2010. Effects of dietary garlic powder and $\alpha$-tocopherol supplementation on performance, serum cholesterol levels, and meat quality of chicken. Poultry Science 89,1724-1731.

Elosta A, Slenin M, Rahman K and Ahmed N. 2017. Aged garlic has more potent antiglycation and antioxidant properties compared to fresh garlic extract in vitro. Scientific Reports 7, 39613. 
Escribano A. 2018. Organic Feed: A bottleneck for the development of the livestock sector and its transition to sustainability? Sustainability 10, 2393.

Fazli N, Hassanabadi A, Mottaghitalab M and Hajati H. 2015. Manipulation of broiler chickens sex differentiation by in ovo injection of aromatase inhibitors, and garlic and tomato extracts. Poultry Science 94, 2778-2783.

Ganhao R, Estévez M and Morcuendeb D. 2011. Suitability of the TBA method for assessing lipid oxidation in meat system with added phenolic-rich material. Food Chemistry 126, 772 778.

Hossain MM, Lee SI and Kim IH. 2014. Effect of dietary Korean aged garlic extract by Leukonostoc citreum SK2556 on production, hematological status, meat quality, relative organ weight, targeted Escherichia coli colony and excreta gas emission in broilers. Animal Feed Science and Technology 198, 333-340.

Issa KJ and Omar MA. 2012. Effect of garlic powder on performance and lipid profile of broilers. Open Journal of Animal Sciences 2, 62-68.

Jahan K, Paterson A, Piggott J and Spickett C. 2005. Chemometric modelling to relate antioxidants, neutral lipid fatty acids, and flavour components in chicken breasts. Poultry Science 84, 158-166.

Jayasena DD, Ahn DU, Nam KC and Jo C. 2013. Factors affecting cooked chicken meat flavour: a review. World's Poultry Science Journal 69, 515-526.

Karim MB, Hossain ME, Ali MS and Hossain A. 2017. Effect of garlic powder (Allium sativum) on growth, dressing parameters, serum biochemical contents and profitability of broiler. Bangladesh Journal Animal Science 46, 215-224.

Kemp SE, Hollowood T and Hort J. 2009. Sensory Evaluation A Practical Handbook. John Wiley \& Sons Ltd, Chichester, West Sussex, U.K.

Kim YJ, Jin SK and Yang HS. 2009. Effect of dietary garlic bulb and husk on the physicochemical properties of chicken meat. Poultry Science 88, 398-405.

Kirkpinar F, Unlu HB, Serdaroglu M and Turp GY. 2014. Effects of dietary oregano and garlic essential oils on carcass characteristics, meat composition, colour, $\mathrm{pH}$ and sensory quality of broiler meat. British Poultry Science 55, 157-166.

Kop-Bozbay C and Ocak N. 2015. Body weight, meat quality and blood metabolite responses to carbohydrate administration in the drinking water during pre-slaughter feed withdrawal in broilers. Journal of Animal Physiology and Animal Nutrition 99, 290-298.

Liu XD, Jayasena DD, Jung Y, Jung S, Kang BS, Heo KN, Lee JH and Jo C. 2012. Differential proteome analysis of breast and thigh muscles between Korean native chickens and commercial broilers. Asian-Australasian Journal of Animal Sciences 25, 895-902.

Majewski M, Kasica N, Jakubowski P and Lepczyńska M. 2017. Fresh garlic juice versus aged garlic extract. Determination of lethal concentration (LC20 and LC50) values on zebrafish (Danio rerio) embryos and larvae. Journal of Elementology 22, 1495-1505.

Mariutti LRB, Nogueira GC and Bragagnolo N. 2011. Lipid and cholesterol oxidation in chicken meat are inhibited by sage but not by garlic. Journal of Food Science 76, 909-915.
Moradi S, Zaghari M, Shivazad M, Osfoori R and Mardi M. 2013. The effect of increasing feeding frequency on performance, plasma hormones and metabolites, and hepatic lipid metabolism of broiler breeder hens. Poultry Science 92, $1227-1237$.

Navidshad B, Maghsoodi Z, Nikbin S, Vahedi V, Adibmoradi M, Aghjehgheshlagh FM and Moradi H. 2018. The compensation effect of dietary garlic on chicken consuming a minimal level of choline. Italian Journal of Animal Science 17, 175-179.

Okada Y, Tanaka K, Sato E and Okajima H. 2008. Antioxidant activity of the new thiosulfinate derivative, S-benzyl phenylmethanethiosulfinate, from Petiveria alliacea L. Organic and Biomolecular Chemistry 6, 1097-1102.

Ozturk E, Ocak N, Turan A, Erener G, Altop A and Cankaya S. 2012. Performance, carcass, gastrointestinal tract, meat quality traits and selected blood parameters of broilers fed diets supplemented with humic substances. Journal of the Science of Food and Agriculture 92, 59-65.

Peinado MJ, Ruiz R, Echávarri Aranda-Olmedo AI and Rubio LA. 2013. Garlic derivative PTS-O modulates intestinal microbiota composition and improves digestibility in growing broiler chickens. Animal Feed Science and Technology 18, 87-92.

Perez-Alvarez JA, Sendra-Nadal E, Sanchez-Zapata EJ and Viuda-Martos M. 2010. Poultry flavour: General aspects and applications, in: Guerrero-Legarreta, I. \& Hu1, Y.H. (Eds) Handbook of Poultry Science and Technology: Secondary Processing, (New Jersey, John Wiley \& Sons) 2, 339-357.

Prati P, Henrique CM, Souza AS, Silva VSN and Pacheco MTB. 2014. Evaluation of allicin stability in processed garlic of different cultivars. Journal of Food Science and Technology 34, 623-628.

Sheoran N, Kumar R, Kumar A, Batra K, Sihag S, Maan S and Maan NS. 2017. Nutrigenomic evaluation of garlic and holy basil leaf powder supplementation on growth performance and immune characteristics in broilers. Veterinary World 10, 121-129.

Sohaib M, Butt MS, Shabbir MA and Shahid M. 2015. Lipid stability, antioxidant potential and fatty acid composition of broilers breast meat as influenced by quercetin in combination with $\alpha$-tocopherol enriched diets. Lipids in Health and Disease 14, 61.

Toghyani M, Toghyani M, Gheisari A, Ghalamkari G and Eghbalsaied S. 2011. Evaluation of cinnamon and garlic as antibiotic growth promoter substitutions on performance, immune responses, serum biochemical and haematological parameters in broiler chicks. Livestock Science 138, 167173.

Weber J, Boshi VC, Ribeiro CP, Victorio AM and Emanuelli T. 2008. Effect of different cooking methods on the oxidation, proximate and fatty acid composition of silver catfish (Rhamdia quelen) fillets. Food Chemistry 106, 140-146.

Wideman N, O'bryan CA and Crandall PG. 2016. Factors affecting poultry meat colour and consumer preferences-A review. World's Poultry Science Journal 72, 353-366.

Zdanowska-Sąsiadek Ż, Michalczuk M, Poławska E, Damaziak K, Niemiec J and Radzik-Rant A. 2016. Dietary vitamin E supplementation on cholesterol, vitamin E content, and fatty acid profile in chicken muscles. Canadian Journal of Animal Science 96, 114-120. 